\title{
TUBEROUS SCLEROSIS COMPLEX IN A FAMILY
}

\author{
MD. AZIZUL HAQUE ${ }^{1}$, LAILA SHAMIMA SHARMI ${ }^{2}$, ARMSAIFUDDIN EKRAM ${ }^{3}$, MD. SAIFUL ISLAM ${ }^{4}$
}

\begin{abstract}
Tuberous sclerosis, also known as tuberous sclerosis complex (TSC), is an autosomal dominant, multisystem, neurocutaneous disorder characterized by development of widespread hamartomatous lesions involving skin, brain, kidney, retina etc. Contrary to the popular belief, the disease has variable degree of expressivity and not all patients have the severe debilitating form. We report two cases of tuberous sclerosis complex in a family and then the literature is reviewed.
\end{abstract}

Keyword: Tuberous sclerosis, neurocutaneous syndrome, hamartoma, phakomatosis

\section{Introduction}

Tuberous sclerosis, also known as tuberous sclerosis complex (TSC), is an autosomal dominant, multisystem, neurocutaneous disorder characterized by development of widespread hamartomatous lesions involving skin, brain, kidney, retina etc. Von Recklinghausen first described tuberous sclerosis in 1862. Bourneville coined the term sclerose tubereuse, to indicate the superficial resemblance of the lesions to potato.

The name of the disease has evolved from this term. ${ }^{1}$ Sherlock coined the term epiloia, encompassing the clinical triad of epilepsy, low intelligence, and adenoma sebaceum. In 1908 Vogt set forth the triad of intractable epilepsy, mental retardation, and adenoma sebaceum. ${ }^{2}$ Unfortunately, this concept led many primary care physicians and even neurologists to conclude, though incorrectly, that a diagnosis of TSC predestines a child to crippling, lifelong neurological and psychological morbidity. Now it is understood that tuberous sclerosis has variable expressivity and not all patients have the severe debilitating form. The term tuberous sclerosis complex (TSC) is now widely used, emphasizing the wide variety of manifestations of the disease.

Mutation of either TSC 1 gene (which encodes hamartin) or TSC 2 gene (which encodes tuberin) is the key to pathogenesis. Hamartin and tuberin heterodimerize and inhibit mTOR, the mammalian target of rapamycin. ${ }^{3,4}$ Hamartin and tuberin are thought to act synergistically to regulate cellular growth and differentiation. ${ }^{5}$ The prevalence is estimated to be one case per 6000 to 10,000 individuals. 6,7

\section{Case report}

A 33 year old lady was admitted in the Department of Medicine, Rajshahi Medical College Hospital with the complaints of skin lesions in face for 24 years and right loin pain for 1 year. Her facial skin lesions first appeared at 9 years of age. Initially she had few skin lesions involving only the face, gradually the number \& areas of involvement increased. Skin lesions were non-itchy, and painless. Her loin pain was dull and dragging in nature, persistent, with no radiation. She gave no history of headache, visual disturbance, and convulsion, impairment of consciousness. Her father, mother, brothers and sisters are healthy and do not have similar problems. She has two children; a boy of 12 years and a girl of one and half years. The boy was healthy, but the girl had 10-12 attacks of convulsion since the age of 1 year. From the history provided by the mother it was evident that, the convulsion was generalized tonic-clonic in nature.

1. Assistant Professor, Department of Medicine, Rajshahi Medical College, Bangladesh

2. Medical Officer, Department of Paediatrics, Rajshahi Medical College Hospital, Bangladesh

3. Professor, Department of Medicine, Rajshahi Medical College, Bangladesh

4. Radiologist, Department of Radiology and Imaging, Rajshahi Medical College, Bangladesh.

Correspondence: Dr. Md. Azizul Haque, Assistant Professor, Department of Medicine, Rajshahi Medical College, Rajshahi. E mail: drazadbd@yahoo.com 
The mother was not anaemic, non-icteric, non oedematous. Her pulse rate was $84 / \mathrm{min}$, regular, BP- $110 / 80 \mathrm{~mm}$ of $\mathrm{Hg}$, respiratory rate $20 / \mathrm{min}$. Her heart was normal, lungs were clear. Adenoma sebaceum- numerous pinhead sized yellowish red translucent discrete waxy papule were found in a butterfly distribution over the face. She also had periungual fibroma affecting her fingers and toes. There were 10 hypomelanotic macules over her back suggestive of ash-leaf macule. Shagreen patches were not present. Fundoscopy was found to be normal. Both the kidneys were bimanually palpable. Both of her children were examined. The boy had no physical findings suggestive of tuberous sclerosis, but the girl had 13 hypomelanotic macules over her chest and back.

Both USG and CT scan of KUB of the mother were reported as suggestive of bilateral angiomyolipoma. CT scan of brain showed multiple subependymal nodules. CXR and echocardiography was reported normal. CT scan of brain of the baby showed multiple cortical tubers and subependymal nodule. Because of unwillingness of the mother no further investigation of the girl could be done.

According to revised diagnostic criteria, definite tuberous sclerosis complex is diagnosed by the presence of 2 major features or 1 major feature plus 2 minor features (Table I). Probable tuberous sclerosis complex is indicated by 1 major feature plus 1 minor feature. Possible tuberous sclerosis complex is indicated by either 1 major feature or 2 or more minor features. ${ }^{8}$ The mother was diagnosed as a case of definite tuberous sclerosis complex as she had five major features of revised diagnostic criteria - facial angiofibromas (Figure 1), periungual fibroma (Figure 2), hypomelanotic macules, renal angiomyolipoma (Figure 3) and subependymal nodule (Figure 4). The baby girl was also diagnosed as a definite case of tuberous sclerosis as she had 3 major diagnostic criteria i.e. hypomelanotic macules (figure 5, 6), subependymal nodules and cortical tuber. The mother was treated symptomatically and girl was treated with sodium valproate. Genetic counseling was provided to the family. The baby was convulsion free when last seen.

\section{Table I}

Revised diagnostic criteria of Tuberous Sclerosis \& clinical manifestation in the mother.

\begin{tabular}{lc}
\hline Major features & $\begin{array}{c}\text { Findings in } \\
\text { our patient }\end{array}$ \\
\hline Facial angiofibromas or forehead plaque & + \\
Nontraumatic ungual or periungual fibromas & + \\
Hypomelanotic macules $\geq 3)$ & + \\
Shagreen patch (connective tissue nevus) & - \\
Multiple retinal nodular hamartomas & - \\
Cortical tuber & - \\
Subependymal nodule & + \\
Subependymal giant cell astrocytoma & - \\
Cardiac rhabdomyoma, single or multiple & - \\
Lymphangiomyomatosis & - \\
Renal angiomyolipoma & +
\end{tabular}

Minor features

Findings in

our patient

Multiple randomly distributed

pits in dental enamel

Gingival fibromas

Confetti skin lesions

Not searched

Multiple renal cysts

Bone cysts

Not searched

Hamartomatous rectal polyps

Not searched

Cerebral white matter radial

Not searched

migration lines

+ denotes present, - denotes absent

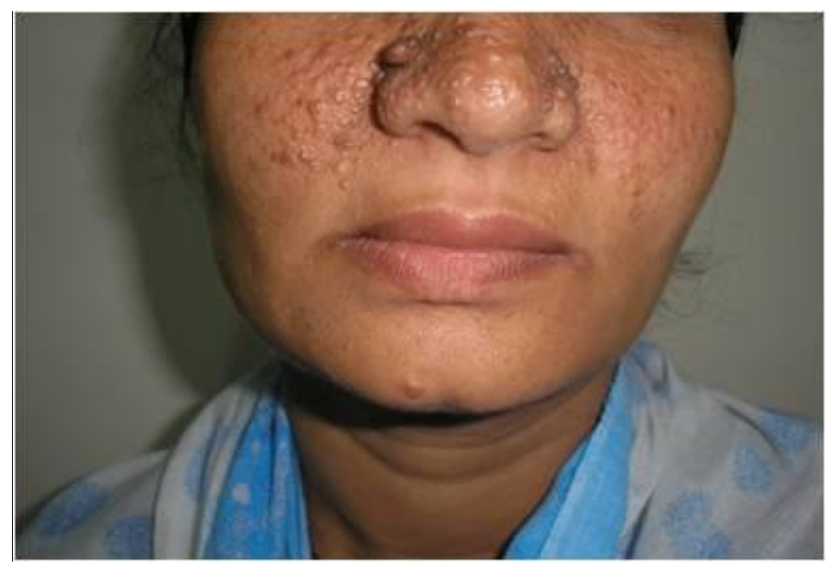

Fig.-1: Adenoma sebaceum 


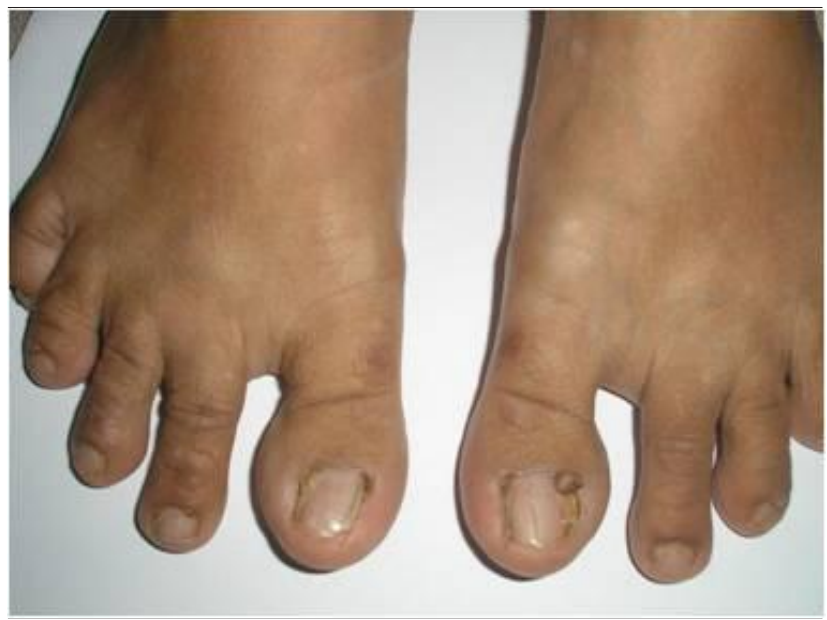

Fig.-2: Periungual fibroma

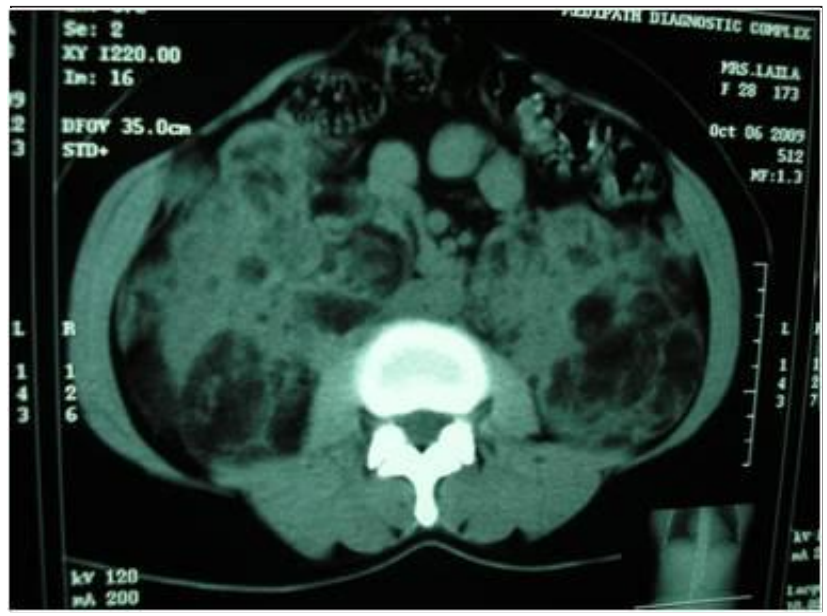

Fig.-3: Bilateral renal angiomyolipoma

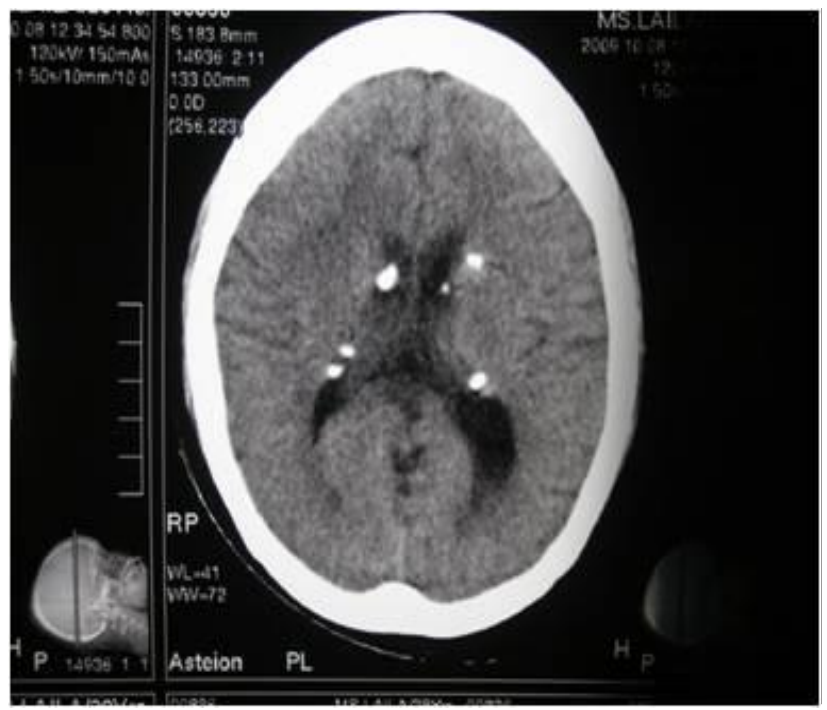

Fig.-4: Subependymal nodule

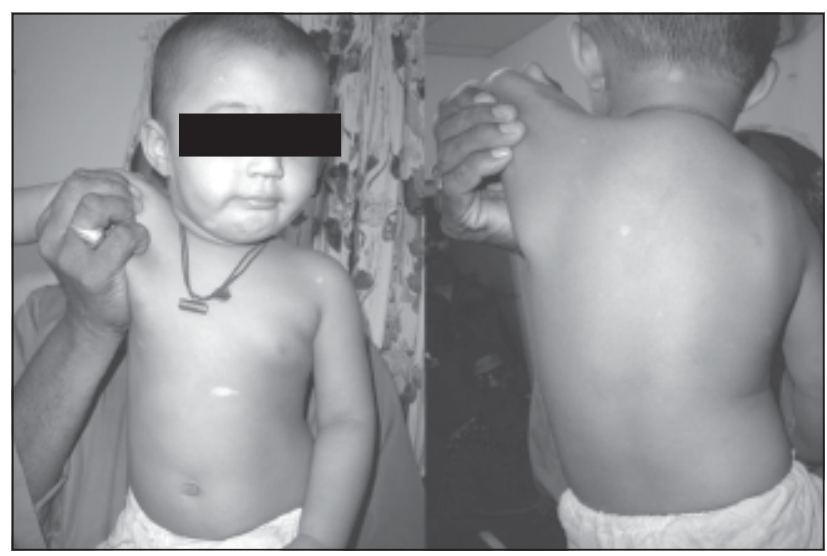

Fig.-5 \& 6: Hypomelanotic macules of the girl

\section{Discussion}

Tuberous Sclerosis is an autosomal dominant disorder with almost complete penetrance but variable expressivity. ${ }^{9}$ Our patient did not have any positive family history; which can be explained by about $65 \%$ new mutation rate of TSC. ${ }^{10}$ Molecular genetic studies have identified two loci for TSC; TSC1 is located on the long arm of chromosome 9 (9q34) and TSC2 is located on the short arm of chromosome 16 (16p13.3). These loci encode for hamartin and tuberin, respectively. ${ }^{11}$ Both TSC1 and TSC2 have tumor suppressor activity, so when TSC 1 or TSC 2 becomes inactive because of mutation, there is uncontrolled cell cycle progression and the proliferation of hamartomas throughout the body. ${ }^{12}$ The expressivity is not determined by the specific gene mutation, because different manifestations can develop in affected members of the same family. ${ }^{13}$

TSC is diagnosed on the basis of revised diagnostic criteria $^{8}$, results of the molecular genetic study is only supportive. Different clinical manifestations of TSC appear at different ages. For example, cortical tubers and cardiac rhabdomyomas form during embryogenesis and they are typically found in infancy. Skin lesions are detected at all ages in more than $90 \%$ of patients with TSC. Hypopigmented macules (formerly known as ash-leaf spots) are generally detected in infancy or early childhood, whereas the so-called Shagreen patch is identified with increasing frequency after the age of 5 years. Ungual fibromas typically appear after puberty and may develop in adulthood. Facial angiofibromas formerly called adenoma sebaceum, may be detected at any age but are generally more common in late 
childhood or adolescence. A subependymal giant-cell tumor of the brain may develop in childhood or adolescence. Renal cysts can be detected in infancy or early childhood, whereas angiomyolipomas develop in childhood, adolescence, or adulthood. Pulmonary lymphangiomyomatosis is found in adolescent girls or women with TSC. ${ }^{14}$

Clinical manifestations of TSC have variable penetrance. For example, as in our cases, the mother has cutaneous manifestations of TSC along with asymptomatic subependymal nodule of brain, but her baby presented with neurological manifestations at 1 year of age. In most patients with TSC there are bilateral renal angiomyolipomas, which are hamartomas composed of abnormal vessels, immature smooth-muscle cells, and fat cells. The estimated incidence of angiomyolipomas in TSC ranges from 55 to $75 \% .{ }^{15}$ Angiomyolipomas may be detected by ultrasonography, computed tomography (CT), or magnetic resonance imaging (MRI). Spontaneous life threatening bleeding can occur as a complication of angiomyolipoma, as they have abnormal vasculature. In general, surgical resection is avoided whenever possible in order to preserve renal function; angiomyolipomas that are more than 3 to $4 \mathrm{~cm}$ in diameter can usually be treated successfully by embolization. ${ }^{16}$

In over $80 \%$ of cases, cortical tubers are present, which are intimately related to neurological manifestations such as include epilepsy, cognitive disability, and neurobehavioral abnormalities, such as autism. ${ }^{17,18,19}$ Tubers are developmental abnormalities of the cerebral cortex characterized histologically by a loss of the normal six-layered structure of the cortex and by dysmorphic neurons, large astrocytes, and a unique type of cell known as a giant cell. ${ }^{20}$ Tubers have been identified in fetuses at a gestational age of 20 weeks. ${ }^{21}$ The lesions persist throughout life but do not become malignant tumors. Tubers can calcify or undergo cystic degeneration. Epilepsy may be the most prevalent and challenging clinical manifestation of TSC. Epilepsy occurs in more than 70 to $80 \%$ of patients with TSC, and virtually all subtypes of seizure (simple partial, complex partial and generalized tonic-clonic seizures) have been reported. Seizures are often refractory to treatment, even to polytherapy with antiepileptic drugs. In most cases, the region in which the seizure originates coincides with the location of a tuber in the brain, and it is widely believed that tubers serve as the epileptogenic focus. Thus, intractable epilepsy is often treated by resection of a tuber. ${ }^{22}$

Thorough dermatological examination should be carried out in all suspected patients; because many of the major and minor features are cutaneous and finding these lesions often lead to the diagnosis. If a child is found to have infantile spasms, cardiac rhabdomyoma, or renal angiomyolipoma he or she should be thoroughly examined for cutaneous manifestations of TSC. If hypomelanotic macules are not evident clinically, the baby should be examined under Wood's lamp.

\section{Conclusion}

TSC is a rare autosomal dominant neurocutaneous disorder. Dermatological manifestations are often the first clue that leads to the diagnosis. Quality of life and morbidity depends upon neurological manifestations of the disease like epilepsy and mental retardation. Though it is not curable, symptomatic treatment and a multidisciplinary approach can improve the quality of life for patients with TSC.

\section{References}

1. Bourneville DM. Sclerose tubereuse des circonvolutions cerebrales: idiotie et epilepsie hemiplegique. Arch Neurol (Paris) 1880;1:81-91. French.

2. Vogt H. Zur Diagnostik der tuberosen Sklerose. Z Erforsch Behandl Jugendl Schwachsinn. 1908; 2:112. German.

3. Povey S, Burley MW, Attwood J, et al. Two loci for tuberous sclerosis: one on 9q34 and one on 16p13. Ann Hum Genet 1994; 58:107-27.

4. Ellisen LW. Growth control under stress: mTOR regulation through the REDD1-TSC pathway. Cell Cycle 2005; 4(11):1500-02.

5. Karbowniczek M, Henske EP. The role of tuberin in cellular differentiation: are B-Raf and MAPK involved? Ann N Y Acad Sci 2005; 1059:168-73.

6. Jozwiak S, Schwartz R, Janniger CK, BielickaCymerman J. Usefulness of diagnostic criteria of tuberous sclerosis complex in pediatric patients. $\mathrm{J}$ Child Neurol 2000;15:652-659.

7. Kandt RS. Tuberous sclerosis complex and neurofibromatosis type 1: The two most common neurocutaneous diseases. Neurologic Clinics of North America 2003; 20:983-1004. 
8. Roach ES, Gomez MR, Northrup H. Tuberous sclerosis complex consensus conference: revised clinical diagnostic criteria. J Child Neurol 1998; 13(12):624-8.

9. Henske EP. Tuberous sclerosis and the kidney: From mesenchyme to epithelium, and beyond. Pediatr Nephrol 2005; 20:854-857.

10. Narayanan V. Tuberous sclerosis complex: Genetics to pathogenesis. Pediatr Neurol 2003; 29:404-409

11. Jozwiak J. Hamartin and tuberin: Working together for tumour suppression. International Journal of Cancer 2006; 118:1-5.

12. O'Callaghan FJK. Tuberous sclerosis: Epidemiological research is needed to complement new findings in genetics. British Medical Journal 1999; 318:1019-1020.

13. Sparagana SP, Roach ES. Tuberous sclerosis complex. Current Opinion in Neurology. 2000; 13:115-119.

14. Crino PB, Nathanson KL, Henske EP. The Tuberous Sclerosis Complex. N Engl J Med 2006; 355:134556.

15. Ewalt DH, Sheffield E, Sparagana SP, Delgado MR, Roach ES. Renal lesion growth in children with tuberous sclerosis complex. J Urol 1998; 160: 141-5.

16. Ewalt DH, Diamond N, Rees C, et al. Long-term outcome of transcatheter embolization of renal angiomyolipomas due to tuberous sclerosis complex. J Urol 2005; 174:1764-6.

17. Thiele EA. Managing epilepsy in tuberous sclerosis complex. J Child Neurol 2004; 19:680-6.

18. Curatolo P, Seri S, Verdecchia M, Bombardieri R. Infantile spasms in tuberous sclerosis complex. Brain Dev 2001;23: 502-7.

19. Prather P, de Vries PJ. Behavioral and cognitive aspects of tuberous sclerosis complex. J Child Neurol 2004; 19:666-74

20. Mizuguchi M, Takashima S. Neuropathology of tuberous sclerosis. Brain Dev 2001;23:508-15.

21. Park SH, Pepkowitz SH, Kerfoot C, et al. Tuberous sclerosis in a 20-week gestation fetus: immunohistochemical study. Acta Neuropathol (Berl) 1997; 94:180-6.

22. Koh S, Jayakar P, Dunoyer C, et al. Epilepsy surgery in children with tuberous sclerosis complex: presurgical evaluation and outcome. Epilepsia 2000; 41:1206- 13. 